Florida International University FIU Digital Commons

HWCOM Faculty Publications

Herbert Wertheim College of Medicine

$10-6-2016$

\title{
Defining the role of a medical student during a sub- internship
}

Dharam Persaud

Herbert Wertheim College of Medicine,„Florida International University, Dpers001@fiu.edu

Frederick Anderson

Herbert Wertheim College of Medicine,, Florida International University, fwanders@fiu.edu

\section{IN COPYRIGHT}

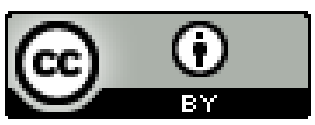

This work is licensed under a Creative Commons Attribution 3.0 License.

Follow this and additional works at: https://digitalcommons.fiu.edu/com_facpub

Part of the Medicine and Health Sciences Commons

\section{Recommended Citation}

Persaud, Dharam and Anderson, Frederick, "Defining the role of a medical student during a sub-internship" (2016). HWCOM Faculty Publications. 37.

https://digitalcommons.fiu.edu/com_facpub/37

This work is brought to you for free and open access by the Herbert Wertheim College of Medicine at FIU Digital Commons. It has been accepted for inclusion in HWCOM Faculty Publications by an authorized administrator of FIU Digital Commons. For more information, please contact dcc@fiu.edu. 


\title{
C Defining the role of a medical student during a sub-internship
}

\author{
Dharam Persaud-Sharma, Frederick Anderson
}

College of Medicine, Florida International University, Miami, FL, USA.

Address for correspondence: Dharam Persaud-Sharma, Herbert Wertheim College of Medicine, Florida International University, Miami, FL, USA Dpers001@fiu.edu

Received: January 15, 2016 Accepted: June 23, 2016 Published: October 06, 2016

\begin{abstract}
Sub-internships (sub-Is) are generally regarded as being highly valued learning experiences and opportunities for matching at a desired residency program. It provides medical students with the opportunity to demonstrate their knowledge and skillset honed throughout their years of medical education. However, many novice students do not have clear guidelines as to how they are perceived by faculty and administration while they are rotating during their sub-l. This is further complicated by

the varying roles of students during an observership, and clinical year core rotations. This brief manuscript aims to provide students with a faculty oriented perspective as to the general expectations of students during clinical training at various stages of their medical education. It is based upon the opinions of a few medical faculty and former residency program directors in family medicine, as well as fourth year medical students reflecting on their sub-l experiences.

While content is not generalizable to all specialties of medicine, the conclusions and opinions are shared and applicable to many specialties of medicine.
\end{abstract}

KEY WORDS: Sub-Internship; Medical Student; Medical Education; Clinical Rotation; Electives.

\section{INTRODUCTION}

In the United States medical education system, a Subinternship (Sub-I) typically refers to an elective clinical rotation that a senior year medical student undertakes at a hospital within a specialty of desired interest to the student. The duration could be anywhere from 2 to 6 weeks, although the average duration is 4 weeks. The traditional role of the student during a Sub-I is to function as a medical intern under the supervision of faculty with increased autonomy yet with reduced responsibilities compared to a true PGY1 resident. The Sub-I provides immense opportunity for learning and for gaining insight into the inner workings of a career in the desired specialty, enabling the student to evaluate if such a career path is feasible.

$\mathrm{n}$ a article published by O'Brien et al. in 2012, surveyed residents reflected upon their 4th year of medical school and the completion of sub-internships. The majority of the residents surveyed agreed that sub-I's are a valuable experience attributable to the level of responsibility and exposure to the role of an intern, providing the mentalpreparation, skill-set, and an enhanced knowledge base to become an intern [2].

Performing sub-I's allows students to reflect upon their own competitiveness and willingness to attain and maintain a position in their desired position [3]. Obtaining a position in the residency position in the area of interest is the first quarter of the challenge to obtaining ones career goals, the remaining $3 / 4$ is enduring and competently completing the residency to embark on successful career. Performing a sub-I enables one to receive critical performance evaluations by attending faculty, allowing the student re-evaluate areas of weaknesses and strengths [3]. More so, a sub-I at a program of interest allows the student to evaluate if the program is conducive to their learning style, lifestyle, educational goals, research endeavors, and clinical training.

\section{DISCUSSION}

While many former medical graduates agree that sub-I's are important in the training of being a physician and obtaining a residency, many medical students do not have a clear understanding of how their performance is evaluated. Generally the role of a medical student during a sub-I is to take on the role of an intern and work effectively with the hospital team in managing patient care.

To begin, sub-I's are very different from a student observership, despite many students treating them the same. An observership is more of a precursor for a student's education in a subject, in this case a particular medical specialty. During an observership, the student should assess patient interviews, assessments, techniques, and procedures. Furthermore, the student should seek to observe the interprofessional interactions of all levels of personnel within the workplace including nurses, physicians, administration, and technicians. As a future member of the complex healthcare environment, understanding such interprofessional relationships are vital to future success. While a student is completing an observership period, it is recommended that the scope of observation not be limited to techniques/procedures or patient interviews/assessments, but should be widened to include the understanding of the workings of a department and the social behaviors of all 
levels of personnel within the workplace including nurses, administration, residents, faculty, physician assistants/ nurse practitioners, and technicians. The main reason for such widened observation is attributable to the social niche created by all of these members to maintain functionality. As a future member of such an environment, understanding such interprofessional relationships are vital to future success. Observerships can be completed by students at all levels of medical education, and best serve those needing an introduction to a discipline.

On the other hand, a sub-internship is reserved for a senior medical student. During this period, which is typically l-month long, students have the opportunity to demonstrate the skills they honed during medical school and learn about more advanced concepts pertinent to their selected field. A comparable analogue to sub-I's include the 3rd year clinical clerkship, where medical students undertake some clinical responsibilities. Likewise, in both sub-I's and clinical clerkships students are evaluated for their performance and their interprofessional collaboration efforts are assessed. Thus, one can conclude if students learn the art of interprofessional collaboration early, they are taking the right steps towards successful sub-I's and the benefits of doing so which includes networking within their desired field, gaining clinical knowledge, and becoming a more polished physician-leader.

Additionally, like third year clinical clerkships, students during a sub-I should focus on absorbing as much information as possible while demonstrating to faculty, residents, and staff that they are capable and worthy of being included in the environmental niche to not only maintain functionality, but that they are capable team players and can make meaningful contributions to improving patient care. As a caveat, a student is not expected to revamp the system, but rather they can focus on making small meaningful changes to help make the system run smoother. Amongst many noteworthy efforts, those recalled by residents and staff to be memorable of rotating students include staying after hours to help the chief resident, pre-rounding on patients with residents, and helping with case presentations if given the opportunity. At the end of the sub-I, students receive a personal evaluation by the faculty, and they have a better perspective on whether that student fits within their system or not. A common misunderstanding that auditioning medical students have is that brown-nosing faculty is necessary to improve the chance of obtaining a position. However, some faculty are particularly sensitive to detecting these intentions by students and such behavior may potentially diminish their chances of obtaining a positive evaluation. Rather than spending a substantial amount of time with faculty, medical students should actively work with residents to be an integral member of the team, and practice effective and professional communication with nurses, staff, and patients because the observed interaction and feedback received from these individuals significantly impact a student's chance of obtaining a positive evaluation which is vital to their future career.
In conclusion, observerships function as an introduction to a field pursued purely by the interest of a student; a sub-I is more like a third year clinical clerkship but more intense and can be likened to a l-month job interview. All three rotations have an important role in the development of a student's medical education and professional development.

\section{CONFLICT OF INTEREST}

The authors declare that they have no conflict of interest.

\section{REFERENCES}

1. Lyss-Lerman P, Teherani A, Aagaard E, Loeser H, Cooke M, Harper GM. What training is needed in the fourth year of medical school? Views of residency program directors. Acad Med. 2009;84(7):823-829.

2. O'Brien, B, Niehaus, B., Teherani, A., Young, J. Resident's perspectives on the final year of medical school. International Journal of Medical Education. 2012; 3: 151-158.

3. Eva Aagaard (2015) Medical Student Advising: Informed Individualized Advice Is the Key. Journal of Graduate Medical Education: September 2015, Vol. 7, No. 3, pp. 486-488.

(c) SAGEYA. This is an open access article licensed under the terms of the Creative Commons Attribution Non-Commercial License (http://creativecommons.org/licenses/by-nc/3.0/) which permits unrestricted, noncommercial use, distribution and reproduction in any medium, provided the work is properly cited.

Source of Support: Nil, Conflict of Interest: None declared 